\title{
SABERES E PRÁXIS EM ENFERMAGEM
}

\section{Knowledges and nursing praxis}

\section{Saberes y praxis en enfermería}

\section{RESUMO}

0 estudo tem como objetivo refletir acerca dos saberes e práxis em Enfermagem pelo diálogo com alguns autores sobre 0 conhecimento, pelo relato da transformação do conhecimento através da história, bem como enfocar a práxis por meio do raciocínio filosófico. A reflexão envolve as várias dimensões do cuidado. Concluímos que a práxis em Enfermagem se constrói libertadora, solidária, emancipatória por se fundamentar no entrelaçamento de saberes e fazeres de um cuidado que converge em ciência, ética, arte e estética.

Palavras-chave: Enfermagem. Conhecimento. Prática Profissional. Cuidados de Enfermagem.

\begin{abstract}
This study aims to reflect on the knowledge and praxis in Nursing through a dialogue with some authors about knowledge, through a report on the transformation of this knowledge in history, as well as to focus on the praxis through philosophical reasoning. The reflection involves the different dimensions of care. We conclude that Nursing praxis is constructed through liberation, solidarity and emancipation, because it is based on the interweaving of knowledge and practice of care that converges in science, ethics, art and aesthetics.
\end{abstract}

Keywords: Nursing. Knowledge. Professional Practice. Nursing Care.

\section{Resumen}

La finalidad del estudio es reflejar sobre los conocimientos y praxis en Enfermería mediante el diálogo con algunos autores sobre el saber, mediante el relato de la transformación del conocimiento a lo largo de la historia, y también enfocar la praxis mediante el raciocinio filosófico. La reflexión abarca las varias dimensiones del cuidado. Concluimos que la praxis en Enfermería se construye libertadora, solidaria, emancipadora por fundamentarse en el entrelazamiento de saberes y haceres de un cuidado que converge en ciencia, ética, ar te y estética.

Palabras clave: Enfermería. Conocimiento. Práctica Profesional. Atención de Enfermería.

'Enfermeira, Doutoranda, Coordenadora do Curso de Enfermagem da Faculdade Católica Rainha do Sertão, Quixadá-CE. Brasil. E-mail: eucleavale@yahoo.com.br, ${ }^{2}$ Enfermeira, Doutora, Professora Titular do Departamento de Enfermagem da Universidade Federal do Ceará. Pesquisadora do CNPq. Brasil.. E-mail: pagliuca@ufc.br, ${ }^{3}$ Mestre, Professor Assistente do Curso de Filosofia da Universidade Federal do Ceará (Cariri-CE). Brasil. Email: regioquirino@yahoo.com.br 


\section{INTRODUCÃO}

A marca da humanidade no mundo é a racionalidade que se apresenta de várias maneiras: técnica, arte, ciência, filosofia e saberes. Todas essas maneiras se encontram na práxis humana, em que a ação é deliberadamente motivada pela idéia, pela teoria. A práxis denuncia a racionalidade humana nas mais diferentes atividades.

No cotidiano da Enfermagem coexistem duas dimensões: a do conhecimento/saber e a da práxis, que diz respeito ao fazer que envolve todo o processo de cuidar em enfermagem. É em nossa práxis que percebemos que o saber é um dos elementos que utilizamos no exercício da profissão de Enfermagem, e este saber possibilita o fazer na perspectiva da ação por meio da competência, habilidade, persistência, paciência e disponibilidade para agir consciente e intuitivamente.

Neste estudo, pretendemos refletir acerca dos saberes e práxis em Enfermagem; para isso, iremos, inicialmente, abordar a visão de alguns autores sobre o conhecimento, como também o processo de transformação do conhecimento em uma perspectiva histórica e a práxis num contexto filosófico. Em um segundo momento, nossa reflexão se direcionará especificamente para a Enfermagem, no que concerne ao campo de conhecimentos e saberes na práxis desta área.

\section{CONHECIMENTO}

A aquisição de conhecimento realiza-se em cada situação social a partir das quais se constituem conhecimentos, competências e habilidades, diretamente vinculadas à vida cotidiana por meio do ensino, da prática e da pesquisa científica fundadas em pressupostos de certeza lógica.

0 conhecimento como parte de nossos recursos cognitivos são representações da realidade ao sabor de nossa experiência e de nossa formação ${ }^{1}$.

Ainda, o conhecimento num sentido muito concreto, representa uma das aventuras mais importantes do ser humano que se confunde com a conquista da emancipação, só possível diante do caráter aventureiro, descobridor, crítico e questionador do ser humano. Atualmente, o conhecimento assume a posição inovadora e estratégica de desfazer as certezas, ao invés de oferecer certezas fundamentadas teoricamente e efetivadas na prática².

Há três princípios de incerteza no conhecimento: ${ }^{3}$

- 0 primeiro é cerebral: o conhecimento nunca é um reflexo do real, mas sempre tradução e construção, isto é, comporta risco de erro;

- O segundo é físico: o conhecimento dos fatos é sempre tributário da interpretação;

- 0 terceiro é epistemológico: decorre da crise dos fundamentos da certeza, em filosofia (a partir de Nietzsche), depois em ciência (a partir de Bachelard e Popper).
0 conhecimento como sabedoria e como orientação vasta e variada possui características muito dinâmicas, delimitadas pelo movimento constante de "desconstrução" e "construção". Corroborando a idéia, o que pode ser visualizado como novo é perspectiva de que o conhecimento, em vez de produzir certezas, é marcadamente uma estratégia de desmontar². Parece ser mais uma habilidade de lidar criativamente com a incerteza, com a qual convive dialeticamente. Já por isso é muito mais um processo interminável de desmonte do que uma fábrica de produtos duradouros. Sua detergência, pois, não é somente um passo inicial, que toda nova teoria, por exemplo, implica, mas a própria razão maior do ser; por quanto cada teoria nova é feita, não para atingirmos algum por to seguro, mas para navegar em frente.

Desconstrução não pode ser vista somente como algo aniquilador, mas como um processo de constante aprendizagem ${ }^{2}$. 0 processo é mais fundamental que o produto gerado, sendo assim, desconstruir e construir é uma práxis humana do conhecimento.

Nesse contexto, estamos lidando com uma área complexa, na qual a busca do conhecimento vai constituir o saber que envolve o pensar, o aprender a aprender e o intervir de modo inovador e ético em diferentes condições operacionais da prática cotidiana.

\section{SÍNTESE DOS ASPECTOS HISTÓRICOS DO CONHECIMENTO}

Para a aproximação com o tema é importante apresentar o contexto que os autores perseguiram para fundamentar suas idéias. A presente seção não pretende ser um apanhado detalhado da transformação histórica do conhecimento, ou uma explicação primeira da fundação do conhecimento, mas um sucinto desenvolvimento histórico e evolutivo, iniciado a partir dos gregos e passando por momentos-chave para a humanidade e sua formação, sobretudo no que diz respeito ao conhecimento.

\section{A ciência e o conhecimento grego}

Para os gregos, a questão do conhecimento era encarada de maneira séria e rigorosa. 0 surgimento da filosofia demonstra exatamente isso. Quando a filosofia, originada pelos gregos, aparece, sua pretensão é de explicar a totalidade das coisas, ou seja, toda a realidade, não deixando partes ou pedaços de realidade fora deste contexto. Deste modo, a filosofia inicialmente contempla a investigação das coisas físicas e depois, e sobretudo, as não-físicas ou metafísicas, como ficou consagrado historicamente na tradição filosófica. Com o surgimento da Filosofia na Grécia, foi marcada uma nova postura dentro do saber humano. Os primeiros filósofos, concentrados na busca da arché, entendida como "um princípio presente em todos os momentos da existência de todas as coisas", ou seja, no início, no desenvolvimento e no fim de tudo do mundo, buscavam compreender a physis, isto é, qual a natureza da 
natureza. Esta investigação era filosófica e "científica", mas é claro que a terminologia científica não tem aqui o mesmo significado da Modernidade; inclusive esta separação não era nem levantada, pois Filosofia e Ciência, na Grécia, formavam uma unidade. A pretensão da Filosofia é a verdade da natureza e do homem. 0 primeiro grande problema a ser revolvido, era o mais elementar de todos. Qual é o princípio de tudo? De onde tudo vem? Os primeiros filósofos eram naturalistas, pois queriam elucidar o princípio (arché) da natureza (physis). Contudo, a pretensão dos filósofos não era simplesmente descobrir coisas, mas descobrir a origem, o princípio, o fundamento das coisas 4 .

Com Aristóteles (384 a.C. a 322 a.C.), por exemplo, principal sistematizador do conhecimento ocidental, desenvolvem-se outras formas de investigação como as ciências práticas (Ética e Política). A fundação da Lógica deve-se também a Aristóteles, como uma forma para o aprimoramento do conhecimento, do discurso que pretende demonstrar algo. Em Aristóteles, a lógica formal se ocupa da estrutura do raciocínio, montando, assim, um procedimento formalmente inquestionável para o argumento, o que contribuiu profundamente para o desenvolvimento das ciências.

Contudo, o conhecimento antigo não tem a pretensão de ser um mero instrumental. 0 desenvolvimento do conhecimento e suas descobertas metafísicas são frutos da sua reflexão em busca da verdade. Algo que está marcado na natureza humana.

\section{Conhecimento na medievalidade}

Ésabido por todos que o período medieval, que compreende historicamente a queda do Império Romano (século $\mathrm{V}$ ) até a queda de Constantinopla (século XV), é marcado profundamente pela discussão teológica, principalmente cristã e, sobretudo, católica. Apesar da predominância das questões religiosas, que levaram os filósofos a discussões sobre a fé, a razão marcou presença nesse período. É importante, neste contexto, o papel desempenhado pelos franciscanos e dominicanos e pela mentalidade e civilização árabes, que formataram o pensamento medieval ${ }^{5}$. Não cabe, então, 0 comentário parcial de que a ldade Média foi a idade das trevas ou da escuridão. A discussão sobre a fé gerou uma intensa produção intelectual e consequente produção de conhecimento. Um conhecimento voltado para a especulação teológica e filosófica em busca da verdade.

0 esforço dos primeiros defensores da religião cristã, que se tornou hegemônica após a aceitação pelo Império romano foi a formatação de um discurso que se contrapusesse ao discurso filosófico grego. A afirmação cristã da identificação ontológica com a pessoa de Deus era o campo de especulação da época. A verdade é uma revelação de Deus e, por consequência, o conhecimento também o é. Agostinho, personagem fundamental na filosofia medieval, afirmava que Deus é verdade. Verdade no sentido de sua existência e de uma natureza que é a própria verdade. 0 confronto com a filosofia grega, a miscigenação com o judaísmo e o discurso contra os hereges promoveram uma efervescência cultural, principalmente no aspecto do conhecimento. Independente da marcante presença teológica, o conhecimento medieval é voltado para a discussão racional e especulativa, sendo praticamente inexistentes a técnica, como se conhece hoje, e a pesquisa empírica. 0 conhecimento permanecia qualitativo como na Antiguidade.

A concepção do ser humano enquanto pessoa éherdeiro do pensamento cristão-medieval; se por um lado as experiências empíricas, principalmente referentes ao corpo humano, eram negadas, pois o corpo era concebido como templo do Espírito Santo e o ser humano imagem de Deus, a construção do conhecimento teórico avançou em alguns aspectos, como na discussão do Eu (Agostinho), da historicidade e da corporalidade do homem e da unidade do homem (Tomás de Aquino), apesar do dogmatismo reinante na época ${ }^{6}$.

No final da Idade Média, percebemos pontos de ruptura com a posição dominante, que preparam, de certa forma, 0 advento de uma nova forma de conhecimento. Esse processo pode também ser entendido, a partir do aparecimento dos centros urbanos e da expansão do comércio, o fim do modo de produção feudal e o surgimento da economia capitalista emergente que necessitará de um conhecimento mais prático.

\section{Conhecimento moderno}

0 homem moderno coloca a si próprio no centro dos interesses e decisões ${ }^{6}$. Da mesma forma, o conhecimento moderno se encontra em um momento de surgimento e amadurecimento cientifico, sem nenhuma dependência que não seja a ele mesmo. Ohomem moderno radicaliza sua subjetividade atomizada, característica que no pensamento antigo e medieval não foi encontrada.

Numa nova ciência não há lugar para explicações que recorram à causalidade divina, como ocorria na astronomia antiga e entidades metafísicas. A ciência é secularizada, abandona a dimensão religiosa que permeia todo o saber medieval. A natureza e o homem começam a ser explicados por vias da metodologia científica, produzindo, assim, uma ampliação e aprofundamento das ciências da natureza e o enquadramento das outras áreas do conhecimento a esta metodologia científica?

Há um novo e radical paradigma para a humanidade. 0 surgimento das ciências modernas e seu caráter prático e intervencionista revolucionam toda sua época e a posteridade. A mensuração, a quantificação e verificação passam a ser elementos que ditam as regras da nova forma de conhecimento.

A Modernidade institui uma razão instrumental, uma racionalidade objetivante, na qual aquilo que se quer saber sobre algo deve ser de total domínio do sujeito, que deve experimentar, refazer o experimento e constatar as verificações de possíveis leis, portanto, um conhecimento positivo da 
realidade. A sociedade moderna se caracteriza como o espaço privilegiado das ciências, no qual "modernização" é sinônimo de "cientifização".

0 conhecimento científico passa a ser a fundamentação última de toda a realidade humana, isto é, aquilo no qual o homem procurava as respostas, a natureza e Deus, deve passar inexoravelmente pela ciência. Com o crivo da racionalidade científica, permanecerá entre nós somente o que for demonstrado cientificamente. A ciência, deste modo, está intimamente ligada à vida do ser humano moderno, é ela que marcará o ser humano, produzindo uma civilização científica e tecnológica. 0 triunfo da técnica tornou o homem o soberano da natureza, capaz de dominar essas forças impetuosas e desfrutá-las para suas prioridades. Com o triunfo da técnica, o homem tornou-se providência para si mesmo, e com isso, para esconjurar a fome, as doenças, as inundações, as epidemias, não recorre, agora, a Deus, como faziam seus antepassados, mas à medicina, à engenharia, à industria, etc.

A ciência moderna com o seu recurso de método rigoroso propõe uma leitura da realidade a partir deste aspecto, isto é, ela reduz a realidade a categorias do seu julgamento lógicoempírico para decifrar o mundo, deixando de lado, uma série de questões que não se enquadram nesta perspectiva. A modernidade rompe com qualquer possibilidade de um conhecimento fora da realidade concreta, portanto metafísica. Esta proposta permeia não só o conhecimento, mas toda a esfera da vida humana: a política, a ética, o trabalho, e assim por diante. Instala-se uma nova ordem, a partir da modernidade, de uma sociedade técnico-científica.

0 cientista assume, na sociedade moderna, um papel de extrema importância. Outrora, esperávamos pelos sinais da natureza, pelos oráculos dos deuses, pelas ordens das autoridades iluminadas por Deus, agora, escutamos os cientistas, a ciência.

Dentro deste contexto, surge uma questão: Será que as ciências deram conta do seu objetivo, de atender as necessidades objetivas do homem no mundo? Foi possível a realização do ser humano, a partir dessa civilização técnicocientífica? A liberdade, enquanto expressão plena da humanidade, foi efetivada?

A racionalidade moderna forma-se como uma racionalidade instrumental, uma razão que tem como fim, a realização das necessidades práticas e objetivas do homem no mundo. Contudo, este mesmo homem no mundo não dá conta do serhomem, deixando de lado aquilo que não pode instrumentalizar.

0 outro passa a ser visto como um objeto, uma coisa a se relacionar. Há uma perspectiva coisificante do homem, que se esvazia de sentido, pois a base dos relacionamentos subjetivos se torna objetivada. Compreender o outro como outro, como possuidor de subjetividade, é a construção de uma intersubjetividade plena, de uma ética, que possibilita uma sociabilidade da realização da comunhão das liberdades, isto é, de uma sociedade de homens, e não de coisas, de uma práxis realmente humana, de uma ciência com e para seres humanos.

\section{SOBRE A PRÁXIS}

Os gregos chamavam práxis a ação de levar a cabo alguma coisa, também designa a ação moral, significa ainda o conjunto de ações que o homem pode realizar, e, neste sentido, a práxis não pode ser entendida como simplesmente prática. A práxis é a união dialética da teoria e ação moral, e ao mesmo tempo em que a razão (teoria) determina o modo como os homens agem, também a ação humana (prática) é projetada, refletida, consciente, racionalizada. Deste modo, o ser humano se autoproduz através desta dialética.

Separar teoria e prática nos gregos não é correto, pois se observa no pensamento grego, por exemplo, em Sócrates, que o ethos (modo de ser) é próprio do ser humano, que é um ser da práxis, pois planeja, raciocina para aplicar o pensamento. Tem-se nos gregos a idéia de que o telos (finalidade) do ethos (modo de ser) humano é efetivado na práxis (ação teorizada e efetivada). Mais um exemplo modelar desta concepção grega de práxis é encontrada em Aristóteles, quando afirma que 0 homem é zôon logikon (animal racional) e zôon politikon (animal político) exatamente por contemplar as dimensões teóricas e práticas que no ser humano não estão divididas ou separadas, mas são unidades da natureza humana.

Éumavisão do ser humano e de seu conhecimento deforma integral, que não fragmenta, seja o próprio homem ou o seu saber. 0 princípio de separação torna-nos talvez mais lúcidos sobre uma pequena parte separada do seu contexto, mas nos torna cegos ou míopes sobre a relação entre a parte e o seu contexto ${ }^{8}$. Deste modo, a práxis é uma manifestação humana que não pode ser mutilada em prol de uma tecnificação, que prioriza somente uma lógica de resultados, ou mesmo cair no ativismo, que também é orientado pela mesma lógica. A práxis humana é o próprio ser humano em todas as suas dimensões e, como tal, não pode ser seccionada.

\section{CONHECIMENTOS E SABERES NA PRÁXIS DA ENFERMAGEM}

Durante muitos anos, a Enfermagem foi considerada uma área do conhecimento em que seus exercentes utilizavam as técnicas como instrumentos do seu saber e fazer em detrimento de suas funções essenciais: o cuidado ao ser humano, a administração do processo de cuidar em Enfermagem e a educação em saúde.

As primeiras manifestações organizadas e sistematizadas do saber na Enfermagem são constituídas pelas técnicas de enfermagem ${ }^{9}$. Elas se organizaram como estrutura de saber nas primeiras décadas do século XX, nos Estados Unidos, umas estiveram sempre presentes nos cuidados de enfermagem e eram tidas como arte de enfermagem.

A Enfermagem moderna organizada por Florence Nightingale, em meados do século XIX, preparou mulheres para atuarem na manutenção da saúde e no cuidado de doentes, utilizando, para tanto, recursos do meio ambiente para manter 
o paciente nas melhores condições para que a natureza agisse sobre ele.

A busca por sua cientificidade fez com que a Enfermagem sofresse a influência de uma filosofia tradicional de ciência, 0 que trouxe reflexos para a prática e para a educação em Enfermagem. Nesse contexto, foi influenciada por normas da ciência comportamental e por normas médicas com ênfase no fazer e permeada por dicotomias: teoria-prática, objetividadesubjetividade, prática-pesquisa, arte-ciência, profissãodisciplina, fazer-saber, cuidar-curar.

No século XX, e com maior força a partir da década de 1950, a Enfermagem buscou ser conhecida como ciência a partir do desenvolvimento de teorias de enfermagem com o objetivo de construir um corpo de conhecimento próprio para explicitação de suas teorias para fundamentar sua prática.

Nas duas últimas décadas do século XX, a Enfermagem procurou superar as limitações do modelo tradicional da ciência e, mais especificamente, do modelo biomédico--mecaniscista dominante na atenção à saúde. Essa mudança fez surgir um cuidado mais subjetivo, com significado pessoal, enfrentando a diversidade das situações do cotidiano, passou a valorizar o estar junto com o outro, o buscar conhecer o outro com suas diferenças sociais e culturais.

No final da década de 1970, a Enfermagem, ao tratar dos fundamentos do conhecimento em enfermagem, identificou quatro padrões de conhecimento: empírico, a ciência da enfermagem, estético, a arte da enfermagem, o pessoal e 0 ético ${ }^{10}$.

0 conhecimento empírico é baseado em fatos, descritivo e fundamentalmente voltado para o desenvolvimento de explicações teóricas e abstratas, replicável, formulado e verificável ${ }^{10}$. Nesta perspectiva, este conhecimento é coerente com a visão tradicional de ciência que predomina na maioria das áreas do conhecimento que conquistaram o reconhecimento da ciência.

Denominamos conhecimento científico quando designamos o padrão empírico de conhecimento e a ciência positivista que ainda predomina. Este criou uma ilusão de estabilidade ao tratar assuntos humanos com muita objetividade, afastando a sensibilidade e colocando a ciência como único caminho para um mundo teórico ${ }^{11}$.

É o conhecimento científico que possibilita a abstração da realidade com a finalidade de sistematizá-la e conseguir fazer uma ligação entre o concreto e o abstrato com a possibilidade de descobrir o real ainda não visualizado e, assim, encontrar as prováveis soluções para os problemas que se referem ao cuidado na atenção à saúde ${ }^{11}$.

0 padrão de conhecimento ético engloba o componente moral que se relaciona com as difíceis escolhas que fazemos no processo de cuidar da saúde de indivíduos, que envolvem questões fundamentais sobre o bem e o mal, o certo e o errado e para os quais, muitas vezes, os princípios, normas e códigos de ética não nos dão respostas ${ }^{10}$. Este conhecimento tem seu foco nos deveres e obrigações, ou mais precisamente sobre 0 que deve ser feito, que inclui todas as ações que invariavelmente estão sujeitas a julgamentos.

0 trabalho na enfermagem envolve planejamento sistematizado e metas a serem alcançadas e estas englobam escolhas norteadas por princípios e normas escritas que, algumas vezes, são conflitantes. Nesse contexto, indagamos: o que fazer? Seguir os princípios e normas escritas ou atender às necessidades do ser humano, respeitando a sua dignidade?

A ética é fundamento decisório para o profissional de enfermagem, pois as decisões do cotidiano de vida e de saúde vêm cotejadas pelo poder instituído, pelo tecnicismo e até mesmo pela sobrevivência do trabalhador, indo além de aspectos técnicos ${ }^{12}$.

0 exercício profissional do cuidado de Enfermagem envolve juízos de valor, decisões e aç̃̃es que suscitam também escolhas pessoais dos profissionais de Enfermagem. É deste contexto que emergem os dilemas éticos e bioéticos, fundamentados em princípios ético-legais e determinados também por escolhas pessoais que podem ser complexas, dependendo da relação e participação do outro no processo de cuidar.

A reflexão ética se propõe a indicar o dever-ser das ações humanas. Esta reflexão está acima de todo código de ética, ou seja, a lei positiva se fundamenta na orientação ética, não podendo haver uma fixação da ação humana, o que pode acontecer é uma normatização. Isto significa que a vida do ser humano não pode ser colocada em risco em virtude da letra, pois na lei a letra só surge pela vida humana, cabendo então a ela, lei, estar a serviço da vida, assim como os cumpridores da lei.

0 envolvimento com o outro vai além da relação enfermeirocliente, para ser uma relação entre seres humanos envolvendo também a equipe de saúde e a instituição de saúde que contempla os elementos administrativos e organizacionais que contribuem para aumentar a complexidade do contexto onde as decisões são tomadas e as escolhas são feitas.

0 cuidado humano, visualizado em sua totalidade, integrando as dimensões do ser (self), o outro e o cosmos, compõe o que se poderia denominar cuidado pessoal e cuidado social, ou seja, a dimensão sujeito-sujeito que se apresenta de duas formas: sujeito-selfe sujeito-outro ${ }^{13}$.

0 conhecimento pessoalé o conhecimento mais difícil para dominar, e, consequentemente, para ensinar, e talvez seja o mais importante na busca da compreensão do significado de saúde em termos de bem-estar individual. Refere-se ao conhecimento do self, ao autoconhecimento, e evidencia o uso terapêutico do self, o que implica que a maneira como as enfermeiras vêem a si mesmas e aos clientes é fundamental em toda relação terapêutica ${ }^{10}$.

Ao compreendermos a expressão "Enfermagem é gente que cuida de gente", o nosso conhecimento deve ser desenvolvido como ação humana, numa relação/interação efetiva entre quem cuida e quem recebe o cuidado, num 
relacionamento pessoal autêntico que requer a compreensão e a aceitação do outro, entendendo que cada pessoa está sempre no processo de vir-a-ser ${ }^{14,15}$.

Neste contexto, o profissional de enfermagem deve cuidar das relações consigo mesmo, compreendendo a sua singularidade como ser humano, passando a ter domínio de si, o que leva a conhecer suas possibilidades e fragilidades, contribuindo para o desenvolvimento de um processo de cuidar/ curar, fundamentado no atendimento das necessidades do ser cuidado, indo além da assistência técnica.

A prática da Enfermagem é a expressão do conhecimento pessoal. Acreditamos que conhecer a si mesmo é fundamental na relação com o outro, tornando possível a aproximação entre o discurso e a prática, e entre o que se é e o que se apresenta $\operatorname{ser}^{16}$. Docentes de enfermagem apontam como metas para a formação do profissional que estes apresentem postura críticareflexiva, humanista e autônoma e, nesta perspectiva, que elaborem conhecimento próprio pela pesquisa ${ }^{17}$.

0 quarto padrão de conhecimento é o estético, em que a empatia é importante para que se possa conhecer a experiência particular e singular da outra pessoa. Este conhecimento envolve a habilidade da enfermeira para entrar em sintonia com o outro e assim possibilitar um cuidado efetivo centrado nas necessidades do outro.

Este conhecimento é subjetivo, individual, único, singular e conduz a aceitação da existência de fenômenos não quantificáveis que são explicados pelas leis e teorias existentes $^{18}$.

A literatura norte-americana revela que o padrão de conhecimento estético envolve a intuição como o conhecimento e sentimento que viabiliza a tomada de decisão sem o uso do recurso do processo analítico consciente ${ }^{19}$.

Acreditamos que o conhecimento intuitivo, visto como conhecimento não racional, diz respeito à interação efetiva que conduz a uma troca de energia entre o ser cuidado e o ser que cuida, numa sintonia que faz com que cuidar seja incorporado pelo ser cuidado.

No Brasil, há referência a outros tipos de conhecimentos: histórico, técnico, humanístico e sócio-político ${ }^{11}$. 0 conhecimento histórico refere-se ao processo evolutivo da Enfermagem ao longo do tempo, o que ocorre na articulação com o contexto no qual ela está inserida, influenciando-o e sendo por ele influenciada. 0 conhecimento humanístico possibilita uma ampla compreensão do ser humano, do que ele sente, percebe e vive, o que conduz a uma redefinição do ser humano.

0 conhecimento sócio-político é descrito como a habilidade de comunicar-se, de mobilizar-se e de participar dos movimentos sociais/coletivos. Assim, a política é vista como uma atitude que direciona as ações e destinações humanas. Este conhecimento é indispensável para a compreensão da ideologia existente nas propostas de saúde, nas relações com as instituições e com os usuários dos movimentos organizados da sociedade.

0 conhecimento sócio-político é fundamental para a compreensão dos outros conhecimentos, pois, enquanto os outros se orientam para "o que", "como" e "para quem" da prática de Enfermagem, o conhecimento sócio-político dirijese para "o onde", deslocando o foco da relação enfermeiracliente, para situar a enfermeira no contexto maior em que têm lugar a Enfermagem e o cuidado em saúde.

Este conhecimento abrange a compreensão do contexto sócio-político das pessoas envolvidas no processo de cuidar em saúde e do contexto sócio-político da Enfermagem e, ainda, a compreensão que a Enfermagem tem da sociedade e de suas políticas.

Este conhecimento também vislumbra as relações entre os profissionais da saúde e da Enfermagem, contemplando as lutas políticas por melhores condições de vida para todos os cidadãos e, ainda, as lutas em prol de condições dignas de trabalho, salário e justiça social.

Acreditamos que a utilização dos nossos saberes que são construídos, desconstruídos e reconstruídos dia-a-dia num processo de reflexão-ação, prática em movimento, teoria em ação constituem a nossa práxis.

É nessa práxis, permeada de situações adversas, mas também de conquistas, que buscamos construir novos caminhos para a Enfermagem. Esses caminhos devem contemplar o exercício da cidadania, que compreende os direitos e deveres que cada indivíduo tem no desenvolvimento de suas funções profissionais individuais e coletivas, e a autorrealização, que deve contemplar a realização pessoal e profissional que se conforma na busca constante da satisfação de suas necessidades de troca de conhecimento, respeito e amor, o que contribui para o reconhecimento profissional, que é fundamental na construção da autorrealização.

Compreendemos que a práxis, entendida como teoria em ação, prática em movimento, inclui a participação na perspectiva de que "a participação é o caminho natural para o homem exprimir sua tendência inata de realizar, fazer coisas, afirmar-se a si mesmo e dominar a natureza e o mundo" 20:16. A participação não pode ser transmitida e sim construída numa vivência coletiva, numa práxis grupal.

A busca pela participação deve ser contínua e implica envolvimento, compromisso, troca, compartilhamento. Portanto, quando envolvemos o nosso paciente no processo de cuidar, além de estimularmos o autocuidado, estamos nos educando e o educando para o exercício da cidadania. 


\section{CONSIDERAÇÕES FINAIS}

0 que dizer sobre saberes? Os saberes se referem ao conjunto de recursos incorporados ao sujeito (conhecimentos, habilidades, qualidades, experiência, capacidades cognitivas, recursos emocionais, etc.) ou recursos do meio (banco de dados, rede de especialistas, redes documentais, etc. $)^{21}$. Há necessidade de distinguir o saber-fazer do saber-agir. 0 saberagir significa ir além do prescrito, por isto está relacionado a uma ação competente, enquanto o saber-fazer é entendido como habilidade.

Os saberes como instrumentos indispensáveis à prática do fazer e do agir de forma eficiente e eficaz correlacionam-se com a técnica. Neste contexto, podemos afirmar que existe uma correlação entre o ser humano e o seu fazer, em que a técnica se torna ferramenta e oferece possibilidades de

\section{REFERÊNCIAS}

1. Perrenoud P. Dez novas competências para ensinar. Porto Alegre (RS): Artmed; 2000.

2. Demo P. Conhecimento moderno: sobre ética e intervenção do conhecimento. Petrópolis (RJ): Vozes; 1997.

3. Morin $\mathrm{E}$. Os sete saberes necessários à educação do futuro. $2^{\mathrm{a}} \mathrm{ed}$. São Paulo (SP): Cortez; 2000.

4. Reale G. História da filosofia: antiguidade e idade média. São Paulo (SP): Paulus; 1990.

5. Peterson MA. Introdução à filosofia medieval. Fortaleza (CE): UFC; 1991.

6. Vaz HCL. Antropologia filosófica I. São Paulo (SP): Loyola; 1991.

7. Koyré A. Estudos de história do pensamento científico. Rio de Janeiro (RJ): Forense Universitária; 1991.

8. Morin E. Da necessidade de um pensamento complexo. Paris (FR): UNESCO; 1999.

9. Almeida MCP, Rocha JSY. 0 saber de enfermagem e sua dimensão prática. São Paulo(SP): Cortez; 1986.

10. Carper BA. Fundamental patterns of knowing in nursing. Adv Nurs Sci 1978; 1(1): 13-23.

11. Trentini M, Paim L. Assistência e pesquisa em enfermagem: uma abordagem convergente-assistencial. Texto\&Contexto Enferm 2001 jan/abr; 10(1): 11-31. ampliação das habilidades humanas, o que implica mudanças concretas sobre o mundo objetivo.

Entendemos que os saberes são incorporados no desenvolvimento das técnicas e que estas se constituem saber prático que viabiliza construção e utilização de instrumentos que possibilitam o desenvolvimento de procedimentos e ações que permitem a operacionalização de uma atividade prática.

Acreditamos que é possível o uso de nossos saberes em todas as suas dimensões, com a perspectiva de uma práxis que se constrói libertadora, solidária, emancipatória, numa via de interação que contempla seres humanos que cuidam e seres humanos que são cuidados, numa sintonia que atende necessidades e faz emergir o entrelaçamento de saberes e fazeres, em que o cuidado faz convergir ciência, ética, arte e estética.

12. Leopardi MT. A finalidade do trabalho da enfermagem: a ética como fundamento decisório. Texto\&Contexto Enferm 1995 jul/dez; 4(2): 23-29.

13. Waldow VR. Cuidado humano: o resgate necessário. Porto Alegre (RS): Sagra Luzzato; 1998.

14. Horta WA. Processo de enfermagem. São Paulo (SP): EPU; 1979.

15. Silva LF. Cuidado de enfermagem em terapia intensiva cardiológica: hermenêutica do conceito fundamentada na fenomenologia Heideggeriana [tese de doutorado] Fortaleza (CE): Faculdade de Farmácia, Odontologia e Enfermagem/ UCE; 2002. 200 f.

16. Rose $P$, Parker D. Nursing: an integration of art and science within the experience of the practiotiner. J Adv Nurs 1994; 20: 1004-010.

17. Rodrigues J, Mantovani MF. 0 docente de enfermagem e sua representação sobre a formação profissional. Esc Anna Nery Rev Enferm 2007 set; 11(3):494-99.

18. McKenna H. Nursing theories and models. London(UK): Routledge; 1997.

19. Silva AL, Baldin SM, Nascimento KC. 0 conhecimento intuitivo no cuidado de enfermagem. Rev Bras Enferm 2003 jan/fev; 56(1): 711.

20. Bordenave JED. O que é participação. São Paulo (SP): Brasiliense; 1983. Coleção Primeiros Passos.

21. Le Boterf G. Desenvolvendo a competência dos profissionais. Tradução de Patrícia Chittoni Ramos Reuillard. Porto Alegre (RS): Artmed; 2003.. 